\title{
INFLUÊNCIA DAS CONEXÕES POLÍTICAS E DA EVIDENCIAÇÃO SOCIOAMBIENTAL NO CUSTO DE CAPITAL
}

\author{
INFLUENCE OF POLITICAL CONNECTIONS AND SOCIAL- \\ ENVIRONMENTAL EVIDENCE ON THE COST OF CAPITAL
}

\section{INFLUENCIA DE LAS CONEXIONES POLÍTICAS Y DE LA EVIDENCIA SOCIOAMBIENTAL EN EL COSTO DE CAPITAL}

Sirlene Koprowski

Mestranda em Ciências Contábeis e Administração da Universidade Comunitária da Região de Chapecó UNOCHAPECÓ

sirlene.koprowski@unochapeco.edu.br

\section{Viviane Krein}

Mestranda em Ciências Contábeis e Administração pela Unochapecó

Pós-Graduada em Planejamento Tributário pela Universidade do Oeste de Santa Catarina (2014)

vivianekrein@unochapeco.edu.br

\section{Rodrigo Barichello}

Doutor em Engenharia de Produção pela Universidade Federal de Santa Catarina/UFSC (2015), com período sanduíche na Universidade do Minho (Portugal) e Centro Alemão de investigação de biomassa (DBFZ German Biomass Research Center gGmbH)

rodrigo.b@unochapeco.edu.br

\section{Sady Mazzioni}

Doutor em Ciências Contábeis e Administração (2015) Mestre em Ciências Contábeis (2005) pela Fundação Universidade Regional de Blumenau - FURB

sady@unochapeco.edu.br

\section{Cristian Baú Dal Magro}

Doutor em Ciências Contábeis e Administração pela Universidade Regional de Blumenau - FURB (2017)

Mestre em Ciências Contábeis pela Universidade Regional de Blumenau - FURB (2012)

crisbau@unochapeco.edu.br

\section{Contextus}

ISSNe 2178-9258

Organização: Comitê Científico Interinstitucional Editor-Chefe: Diego de Queiroz Machado Avaliação: double blind review pelo SEER/OJS

Recebido em 11/02/2019

Aceito em 01/04/2019

Versão final em 02/05/2019

http://dx.doi.org/10.19094/contextus.v17i2.40358

\section{RESUMO}

O objetivo do estudo é verificar a influência das conexões políticas e da evidenciação socioambiental no custo de capital das empresas. A amostra da pesquisa foi composta de 275 empresas listadas na B3. Os achados revelam que: a) o nível de evidenciação socioambiental influencia positivamente o custo de capital das empresas, principalmente o custo de capital de terceiros; b) as conexões políticas, isoladamente, influenciam negativamente o custo de capital próprio e positivamente o custo de capital de terceiros; c) e moderam negativamente, a relação entre a evidenciação socioambiental e o custo de capital próprio. Portanto, as conexões políticas reduzem o retorno dos acionistas, criam restrições pelas instituições de crédito que exigem maior custo de capital e tornam-se maléficas para as empresas, ao coibirem o efeito das práticas socioambientais no retorno de capital próprio.

Palavras-chave: evidenciação socioambiental; custo de capital; sustentabilidade; disclosure; conexões políticas. 


\begin{abstract}
The objective of the study is to verify the influence of political connections and socioenvironmental disclosure on the cost of capital of companies. The survey sample consisted of 275 companies listed in B3. The findings reveal that: a) the level of social and environmental disclosure positively influences the cost of capital of companies, especially the cost of third-party capital; b) political connections, in isolation, negatively influence the cost of capital and positively the cost of capital of third parties; c) and moderate negatively, the relationship between socioenvironmental disclosure and cost of equity. Therefore, political connections reduce shareholder returns, create constraints on credit institutions that require a higher cost of capital and become harmful to companies by curbing the effect of socio-environmental practices on the return of equity.
\end{abstract}

Keywords: socioenvironmental disclosure; cost of capital; sustainability; disclosure; political connections.

\title{
RESUMEN
}

El objetivo del estudio es verificar la influencia de las conexiones políticas y de la evidencia socioambiental en el costo de capital de las empresas. La muestra de la encuesta fue compuesta de 275 empresas listadas en la B3. Los hallazgos revelan que: a) el nivel de evidencia socioambiental influye positivamente en el costo de capital de las empresas, principalmente el costo de capital de terceros; b) las conexiones políticas, aisladamente, influencian negativamente el costo de capital propio y positivamente el costo de capital de terceros; c) y moderan negativamente, la relación entre la evidencia socioambiental y el costo de capital propio. Por lo tanto, las conexiones políticas reducen el retorno de los accionistas, crean restricciones por las instituciones de crédito que exigen mayor costo de capital y se vuelven maléficas para las empresas, al cohibir el efecto de las prácticas socioambientales en el retorno de capital propio.

Palabras clave: evidencia socioambiental; coste de capital; sostenibilidad; divulgación; conexiones políticas.

\section{INTRODUÇÃO}

A consciência pela sustentabilidade estabeleceu-se firmemente nas organizações. Este tipo de comportamento organizacional ganha reputação junto ao mercado, pela crença de maior eficiência na administração financeira e nos investimentos (PEIXOTO et al., 2016). Portanto, a postura de responsabilidade social corporativa (RSC) é preocupação central das organizações que almejam crescimento harmônico com as partes interessadas (ASHLEY, 2005).

Nesse sentido, os stakeholders pressionam as corporações para adotar postura que ultrapasse os limites meramente econômicos. As regulamentações, protocolos ambientais e as exigências pela transparência têm aumentando o interesse do mercado nas práticas socioambientais adotadas pelas empresas. Ashley (2005) indica que a adoção de uma postura ética e de responsalidade social e ambiental tem melhorado a competividade organizacional.

As empresas divulgam informações de natureza voluntária para valorizar suas ações de RSC, tendo em vista que a evidenciação obrigatória, geralmente, focaliza nas informações econômicas (ROVER; BORBA; MURCIA, 2009; MATOS et al., 2011; FERNANDES, 2012). Portanto, a divulgação voluntária reduz a assimetria informacional (HOEPNER et al., 2016) e, tem sido um importante elo entre as empresas e suas partes interessadas, promovendo influência no reconhecimento de riscos e retornos sobre investimentos, fatores que são inevitáveis para a liberação de crédito financeiro e na atração de investidores (FENG, 2012). 
Para tanto, a evidenciação socioambiental pode reduzir o custo capital de terceiros, por meio de dois canais principais: redução substancial do risco e mitigação da seleção adversa (GOSS; ROBERTS, 2011; REVERTE, 2012; GE; LIU, 2015). Por outro lado, Sharfman e Fernando (2008) afirmam que quando os credores percebem altos níveis de riscos divulgados nos relatórios socioambientais, podem exigir taxas de juros mais elevadas para estas empresas. Rover, Borba e Murcia (2009) também já mencionaram os efeitos maléficos da divulgação de informação desfavorável (riscos) nos relatórios de RSC.

O mercado de capitais também reage às empresas que adotam uma postura de RSC frente as práticas socioambientais (DEEGAN; RANKIN, 1996; BERTHELOT; CORMIER; MAGNAN, 2003; RIBEIRO; NASCIMENTO; BELLEN, 2009). A consequência da imagem positiva percebida pelo mercado provoca aumento no preço das ações destas empresas, fazendo com que o capital dos acionistas seja melhor remunerado (IUDÍCIBUS; LOPES, 2004; LOPES; MARTINS, 2005; MATOS et al., 2011; GHOUL et al., 2011).

Tais indícios apontam uma relação de interdependência entre a sustentabilidade corporativa e sua evidenciação, com o custo de capital próprio e/ou de terceiros, pois a evidenciação socioambiental pode reduzir os custos de transação (assimetria informacional), aumentar a liquidez das ações e diminuir os riscos e as incertezas (RICHARDSON; WELKER, 2001). Dessa forma, o custo de capital é uma medida que capta, adequadamente, o papel da divulgação voluntária e mensura a função primária de fornecer informações relevantes na avaliação e alocação de recursos (BARROS et al., 2017).

Estudos anteriores que avaliaram o efeito da divulgação socioambiental no custo de capital das empresas apresentaram resultados inconclusivos e divergentes, apontando três vertentes diferentes: a evidenciação socioambiental está associada ao aumento no custo de capital (LIU; VILLIERS, 2011); relações neutras, em que não é possível identificar os impactos da divulgação no custo de capital (CANELA; MARIETTO, 2017; HOEPNER et al., 2016); e variações negativas, que apontam um menor custo de capital diante de maiores informações alinhadas à sustentabilidade (FERNANDES, 2012; PEIXOTO et al., 2016).

Ademais, indícios apontam que a governança corporativa (GC) faz com que a empresa tenha compromisso com a responsabilidade social corporativa (RSC), fazendo com que haja maior eficiência na evidenciação socioambiental (BRINKERHOFF, 2000; JAMALI; SAFIEDDINE; RABBATH, 2008; AGUILERA et al., 2007; KAYMAK; BEKTAS, 2017). A Teoria dos Stakeholders postula que a CG exige dos gestores diligência com todas as partes 
interessadas da firma (FREEMAN; EVAN, 1990; SPITZECK; HANSEN, 2009).

Complementarmente, Jensen e Meckling (1976) indicam que as firmas devem usar a RSC como extensão dos mecanismos de GC para divulgar informações voluntárias que minimizem os conflitos de agência. Os autores abordam também que, a GC pode ser impactada pelos fatores sociais e políticos do ambiente. Para tanto, a estrutura de propriedade das empresas pode modificar a forma de atuação da GC frente a RSC. Neste caso, as conexões políticas, por meio da estrutura de propriedade ou por doações de empresas para campanhas, podem contrapor aos interesses dos mecanismos de GC, exercendo um efeito maléfico para o retorno dos acionistas (BREY et al., 2011; CAMILO; MARCON; BANDEIRA DE MELLO, 2012).

Os financiadores do capital tendem a cobrar remunerações diferenciadas de empresas com conexões políticas (SANTOS, 2017), admitindo que tais organizações podem apresentar ineficiência na gestão dos recursos (TEE, 2018; BOUBAKRI et al., 2012). Evidências encontradas por Boubakri et al. (2012) apontam que os investidores demandam menor custo de capital nas empresas com conexões políticas. Li e Liu (2018) apontam que este tipo de empresa utiliza a RSC, pela evidenciação socioambiental, para angariar recursos, contudo, este efeito não é refletido no retorno do capital investido pelos acionistas.

Isso pode ser explicado pela necessidade das empresas com conexões políticas satisfazem os interesses políticos em detrimento dos econômicos e competitivos. As conexões políticas podem afetar a imagem da empresa frente as instituições de crédito, que pelo risco associado ao negócio cobram maiores taxas de juros (JACKOWICZ; KOZLOWSKI; MIELCARZ, 2014; BORISOVA et al., 2015; LIEDONG; RAJWANI, 2017).

Tendo em vista que as conexões políticas afetam o compromisso com a RSC pela evidenciação socioambiental e, que isso está atrelado ao prejuízo na remuneração do capital de acionistas e também ao aumento nas taxas de juros dos financiadores, torna-se relevante a seguinte problemática de pesquisa: qual a influência das conexões políticas e da evidenciação socioambiental no custo de capital das empresas? O objetivo do estudo consiste em verificar a influência das conexões políticas e da evidenciação socioambiental no custo de capital das empesas. Adicionalmente, analisa-se o efeito moderador entre a evidenciação socioambiental e as conexões políticas no custo de capital das empresas (LI; LIU, 2018).

A principal justificativa do estudo baseia-se na importância de se analisar o comportamento das empresas diante das características do cenário brasileiro, marcado pela alta concentração acionária, fraca proteção aos acionistas minoritários, expressiva participação do 
governo na estrutura de propriedade das empresas e alta percepção de corrupção pela sociedade. Tais fatores, relacionados com a maior assimetria informacional, podem culminar em baixo nível de evidenciação, e consequentemente, influenciar o custo de capital (BIZELLI; ALBUQUERQUE; SOUZA, 2017). Além disso, a RSC pode ser exercida por meio da evidenciação socioambiental e que as conexões políticas também podem ter interesse neste tipo de informações pela reputação que buscam junto a sociedade, investidores e acionistas e, desta maneira, os fatores apontados podem representar a consecução de recursos com custo diferente.

\section{REFERENCIAL TEÓRICO E DESENVOLVIMENTO DAS HIPÓTESES}

A evolução dos mercados expandiu os horizontes e trouxe desafios para a contabilidade, reafirmando sua relevância perante à sociedade. Nos últimos anos, as mudanças na regulamentação contábil exigiram das empresas um maior nível de evidenciação de informações acerca da RSC (ROVER, 2013).

A evidenciação de informações pode ser obrigatória ou voluntária, sendo que, geralmente, a alternativa voluntária transcende os aspectos financeiros, econômicos e quantitativos, abrangendo dados de natureza qualitativa. Dentre as informações de natureza voluntária estão aquelas direcionadas à sustentabilidade empresarial. A divulgação de informação socioambiental conecta a empresa aos seus diversos stakeholders, dentre eles, a própria sociedade (BARROS et al., 2017; RIBEIRO; NASCIMENTO; BELLEN, 2009). Adicionalmente, o mercado de capitais reage positivamente frente as empresas com disclosure ambiental (RIBEIRO; NASCIMENTO; BELLEN, 2009).

Ademais, a competitividade pressiona as empresas a implementarem práticas sustentáveis como uma oportunidade de diferenciação (PEIXOTO et al., 2016). Nesse sentido, maiores níveis de divulgação de informação socioambiental reduzem a assimetria informacional, alavanca a credibilidade e a confiança dos credores, contribuindo com o acesso ao crédito (ROVER, 2013; ALMEIDA; SANTOS, 2016). Ademais, os investidores têm preferência pelas empresas com divulgação de informações socioambientais, por acreditarem no menor nível de informações ocultas associadas aos riscos dos negócios (GUENSTER et al., 2011), os quais decorrem da redução de assimetria informacional, seleção adversa e, consequemente, do risco percebido pelos investidores (ROVER; BORBA; MURCIA, 2009).

Como consequência, empresas com nível elevado de divulgação socioambiental aumentam a liquidez das ações e a remuneração sobre o capital próprio dos acionistas (ROVER, 
2013). Belkaoui (1976) assevera que existem problemas ambientais que afetam os lucros por ação, atuando diretamente no aumento dos custos operacionais e indiretamente no crescimento dos riscos esperados para o negócio. Isso é refletindo na expectativa de lucratividade dos investidores que reagem a tais informações. Lorraine et al. (2004) também acharam evidências de que o preço das ações reage à evidenciação de informações ambientais.

Epstein e Freedman (1994) identificaram que 82,17\% dos investidores desejam informações sobre evidenciação ambiental nos relatórios anuais. Sobre isso, Deegan e Rankin (1996), Berthelot, Cormier e Magnan (2003) e Ribeiro, Nascimento e Bellen (2009) acentuam que a informação ambiental é percebida pelos investidores como a mais importante fonte de informação no que concerne à interação da empresa com o seu ambiente e, por isso o mercado de capitais apresenta reações positivas ao disclosure ambiental.

Iudícibus e Lopes (2004) e Lopes e Martins (2005) observam que uma consequência dessa divulgação voluntária é o impacto no preço das ações e Guenster et al. (2011) destacam que grandes investidores estão demonstrando preferência para reportar seus investimentos às organizações que tenham atividades socialmente responsáveis. Feldman et al. (1997) apontam que as firmas com melhor desempenho ambiental apresentam menos riscos aos investidores, ao passo que Ghoul et al. (2011) concluíram que a RSC influencia o custo de capital próprio, nos preços das ações e nas previsões de lucros pelos analistas.

Canela e Marietto (2017) examinaram empresas brasileiras que adotaram os elementos da sustentabilidade empresarial nas estratégias de negócios e os efeitos no custo de capital próprio. Os resultados apontam que não ocorreu queda significativa no custo de capital próprio, apontando uma relação neutra entre os investimentos em RSC e o custo de capital próprio.

Por outro lado, ao estudar empresas australianas e do Reino Unido, Liu e Villiers (2011) encontraram evidências de que a adoção das Diretrizes do GRI esteve associada ao aumento no custo de capital próprio. Ao resultado, atribuíram duas razões: devido à assimetria informacional os acionistas consideram que os custos para a produção da informação superam os seus potenciais benefícios. Adicionalmente, empresas com comportamento sustentável assumem compromissos com a proteção ambiental, fator que propicia redução nos custos regulatórios e de litígios. Isso faz com que estas empresas tenham resultados mais satisfatórios e maior retorno sobre o capital investido (LIU; VILLIERS, 2011).

Matos et al. (2011) justificam que uma necessidade crescente do relato de informações voluntárias é a liquidez do mercado de ações e a busca crescente pelos títulos de crédito 
oriundos de empresas com maior divulgação voluntária, fatores que impactam no maior custo de capital próprio, ou seja, maior retorno aos investidores.

Sendo assim, se a RSC pela evidenciação de informação socioambiental tem poder para determinar o nível de retorno do capital dos acionistas, também pode ser responsável pela forma com que as instituições financeiras oferecem crédito. Nesse sentido, Goss e Roberts (2011) e Ge e Liu (2015) evidenciaram que a RSC está associada ao menor custo da dívida. Peixoto et al. (2016) investigaram os efeitos da adesão ao Índice de Sustentabilidade Empresarial (ISE), por empresas brasileiras de capital aberto, sobre o custo de capital e endividamento, no período de 2009 a 2013. Constataram que as empresas que aderem ao ISE buscam reputação perante a sociedade, revelando relações negativas com o custo de capital e o endividamento.

Em estudo com empresas brasileiras, Fernandes (2013) demonstrou que a RSC pelos disclosure voluntário ambiental não afetava o custo da dívida. Já Hoepner et al. (2016) verificaram a relação entre sustentabilidade empresarial do país e o custo dos empréstimos bancários em 28 países, entre 2005 a 2012, constatando que a sustentabilidade do país afeta o financiamento direto da atividade econômica. No entanto, não encontraram evidências conclusivas de que a sustentabilidade, em nível de empresa, influencia a taxa de juros cobrada pelos bancos.

Gray e Bebbington (2001) apontam as informações ambientais afetam a relação entre empresas e instituições de crédito. Os bancos, por exemplo, estão interessados no risco de crédito e potenciais contingências que possam recair sobre a empresa que busca o crédito financeiro. Gray e Bebbington (2001) garantem que a tendência de evidenciar informações ambientais para o setor financeiro segue em diversas direções, tais como: contingências passivas; provisões; diminuição extraordinária ou excepcional do lucro; e comentários operacionais e financeiros sobre questões ambientais que afetam a empresa.

A evidenciação socioambiental pelas empresas oportuniza às instituições financeiras a obtenção de informações adicionais acerca dos riscos atrelados aos negócios e, diante de tal situação podem oferecer crédito com taxas de juros menos atrativas às empresas que divulgam determinadas informações socioambientais. Assim, considera-se que as instituições financeiras são privilegiadas com a informação socioambiental divulgada pelas empresas, podendo utilizarse disso para oferecer recursos financeiros a um elevado custo.

Nesse sentido, Sharfman e Fernando (2008) afirmam que níveis mais elevados de gestão de risco socioambiental fazem com que as empresas incorram em maior custo de dívida com 
capital de terceiros. Rover, Borba e Murcia (2009) também mencionaram sobre o efeito negativo na divulgação de informação desfavorável nos relatórios de RSC.

Corroborando os fatos, tem-se que as empresas que atuam em setores de alto impacto são pressionadas a divulgar, em maior escala, informações socioambientais para não sofrerem sanções de seus investidores e agências financiadoras, por conta de uma má reputação prévia, em decorrência do seu impacto negativo ao meio ambiente e a sociedade (REVERTE, 2012). Presume-se, a pré-disposição destas companhias a terem bons níveis de divulgação de tais informações, e consequentemente, o efeito desse repasse informacional sobre custo de capital seja mais pronunciado (REVERTE, 2012; LI; LIU, 2018), admitindo a seguinte hipótese:

H1: As empresas com maior nível de evidenciação socioambiental aumentam (aumentam) o custo de capital próprio (custo de capital de terceiros).

No Brasil, pela conjuntura das boas práticas da GC, percebe-se avanços na transparência, prestação de contas e atendimento às imposições dos stakeholders (FREEMAN; EVAN, 1990; BIZELLI; ALBUQUERQUE; SOUZA, 2017). Portanto, as empresas devem manter suas atividades em sintonia com as aspirações éticas, legais e comuns da sociedade, recaindo no domínio da RSC (JAMALI et al., 2008).

A abordagem de RSC equilibra as necessidades de diferentes grupos com os objetivos dos acionistas, incorporando um quadro de GC com preocupações nas áreas social, ambiental e pública. Percebe-se que há convergência nos temas de GC e RSC, em que ambos buscam garantir à resistência dos negócios (AGUILERA et al., 2007). Jamali et al. (2008) com base em entrevistas com gestores do topo de oito empresas que operam no Líbano, sugerem que a GC pode ser um pilar para a sustentabilidade da RSC.

Aguilera et al. (2007) afirmam que, tanto a GC quanto a RSC, são manifestações das firmas sobre suas responsabilidades morais com as partes interessadas. A RSC pode ser vista como uma extensão da firma para promover a eficácia da GC, garantindo a sustentabilidade pelas práticas empresariais que promovam a responsabilidade e transparência não apenas aos acionistas, mas para toda sociedade (JO; HARJOTO, 2012).

Vale ressaltar que a GC transcende o nível de informação recomendado pela legislação vigente, apresentando-se como uma altertativa estratégica das empresas (BALLESTERO; NOGUEIRA; VITORINO FILHO, 2016). Contudo, Jensen e Meckling (1976) aduzem que a GC pode ser impactada pelos fatores sociais e políticos do seu ambiente. Sendo assim, a 
estrutura de propriedade das empresas pode ser moldada pelo interesse dos indivíduos, fazendo com que a atuação da GC seja fragilizada e, consequentemente a própria RSC.

Neste contexto, as conexões políticas intrínsecas à estrutura de propriedade podem trazer efeitos danosos para a atuação da GC e, como consequência prejudicar o retorno do capital investido pelos acionistas (BREY et al., 2011; CAMILO; MARCON; BANDEIRA DE MELLO, 2012). Além disso, as instituições de crédito acabam aplicando maiores taxas de juros sobre empréstimos oferecidos às empresas conectadas ao governo (SANTOS, 2017), admitindo que estas são ineficientes na aplicação dos recursos (TEE, 2018; BOUBAKRI et al., 2012).

Evidências encontradas por Boubakri et al. (2012), apontam que investidores ganham menor remuneração sobre o capital nas empresas com conexões políticas. Li e Liu (2018) apontam que as empresas com conexões políticas podem se utilizar da RSC pela evidenciação socioambiental para angariar recursos, os quais podem ser aplicados com ineficiência trazendo menor retorno ao capital investido pelos acionistas.

As conexões políticas podem resultar em maior propensão das empresas em satisfazerem as necessidades políticas, como por exemplo, empregar políticos não qualificados e/ou aumentar os salários de colaboradores politicamente conectados. Estes fatores prejudicam o desempenho e podem influenciar no aumento do custo da dívida nas empresas (JACKOWICZ; KOZLOWSKI; MIELCARZ, 2014; LIEDONG; RAJWANI, 2017).

Borisova et al. (2015) investigaram o impacto das conexões políticas, por meio da participação acionária do governo, sobre o custo da dívida corporativa. A amostra final consistiu em 226 empresas de 43 países e os resultados indicaram que a participação do governo aumenta o custo da dívida nas empresas.

Liedong e Rahwani (2017) examinaram o impacto das conexões políticas no custo da dívida em Gana, em 179 empresas. As descobertas mostraram uma relação positiva entre as conexões políticas e o custo da dívida, fator que se torna mais pronunciado quando as empresas conectadas fazem empréstimos de bancos privados e mais fracas quando efetuam empréstimos a bancos de propriedade do governo. Desse modo, as conexões políticas estão associadas com altas taxas de juros. Portanto, tem-se a seguinte hipótese:

H2: As empresas com conexões políticas reduzem (aumentam) o custo de capital próprio (custo de capital de terceiros). 
Diante das evidências, percebe-se o efeito maléfico das conexões políticas na GC e, consequemente, na assimetria informacional e junto as partes interessadas. Assim, de um lado, as empresas com conexões políticas afetam negativamente a relação positiva entre evidenciação socioambiental e o custo de capital próprio, tendo em vista que as conexões políticas trazem perda de competividade e pioram o retorno sobre o capital investido pelos acionistas.

De outro lado, as empresas com conexões políticas afetam positivamente a relação positiva já existente entre a evidenciação socioambiental e o custo de capital de terceiros. Sendo assim, as empresas com conexões políticas aumentam ainda os riscos percebidos pelas instituições financeiras naquelas empresas com divulgação socioambiental. Este fator mostra a possível visão de ineficiência neste tipo de organização e o cuidado das instuitões de crédito com os riscos relatados na evidenciação socioambiental.

As empresas com conexões políticas possuem maior proteção governamental, quanto a eventuais incertezas de mercado, controle regulatório menor, concessão de benefícios para pagamento de encargos fiscais menores, entre outros, que colocam estas companhias em situação de privilégio (TEE, 2018; BOUBAKRI et al., 2012).

Estes privilégios fazem com que estas empresas com conexões políticas tenham menor preocupação com as partes interessadas, gerando maior conflito de agência entre gestores e acionistas, bem como frente as instituições financeiras. Sendo assim, mesmo que as empresas com conexões políticas tenham um elevado nível de evidenciação socioambiental, isso pode não ser refletido no retorno do capital investido pelos acionistas. Além disso, as empresas com conexões políticas podem piorar ainda mais o risco percebido pelas instituições de crédito sobre as empresas com evidenciação socioambiental de tais fatores. Sendo assim, tem-se a seguinte hipótese de pesquisa.

H3: As conexões políticas afetam negativamente (positivamente) a relação entre evidenciação socioambiental e o custo de capital próprio (custo de capital de terceiros).

A expectativa na formulação desta hipótese é que, empresas com conexões políticas, por meio de doações ou pela participação do governo em sua propriedade, são beneficiadas com privilégios excedentes, em comparação as demais empresas. Esse cenário impõe uma sensação de insegurança ao capital dos investidores, mesmo quando existe alta evidenciação socioambiental e, também as demais fontes de financiamento (CAMILO; MARCON; BANDEIRA DE MELLO, 2012; PINHEIRO; LUCA; VASCONCELOS, 2016). 


\section{METODOLOGIA}

A população corresponde às empresas de capital aberto listadas na B3, exceto as pertencentes ao setor financeiro. O custo de capital próprio no setor financeiro se difere pela rentabilidade no preço das ações e, consequentemente, na remuneração aos acionistas. Ademais, o custo de capital de terceiros também se diferencia, tendo em vista que o crédito fornecido aos outros setores advém do próprio setor financeiro. Sendo assim, a amostra final ficou composta de 275 empresas listadas na B3, que continham os dados necessários para operacionalizar as variáveis propostas no estudo.

O Quadro 1 apresenta as métricas utilizadas para o cálculo das variáveis dependentes.

Quadro 1 - Variáveis Dependentes

\begin{tabular}{|c|c|c|c|}
\hline Descrição & Métrica & Fonte & Autores de base \\
\hline $\begin{array}{l}\text { Custo de Capital } \\
\text { de Terceiros } \\
\text { (CCT) }\end{array}$ & $\begin{array}{l}\quad \text { Despesas Financeiras / Dívida Bruta } \\
\text { Dívida Bruta = Empréstimos e Financiamentos de } \\
\text { Curto e Longo Prazo + Debêntures de Curto e } \\
\text { Longo Prazo }\end{array}$ & \multirow{2}{*}{ 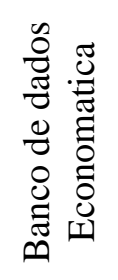 } & $\begin{array}{l}\text { Nardi et al. (2009); } \\
\text { Fonseka, Rajapakse } \\
\text { e Richardson (2018) }\end{array}$ \\
\hline $\begin{array}{c}\text { Custo de Capital } \\
\text { Próprio (CCP) }\end{array}$ & $\frac{\text { Dividendos }+ \text { Juros sobre Capital Próprio }}{\text { Patrimônio Líquido }}$ & & $\begin{array}{l}\text { Forti, Peixoto e } \\
\text { Alves (2015) }\end{array}$ \\
\hline
\end{tabular}

Fonte: elaboração própria.

Quanto às métricas adotadas, considerou-se o custo já incorrido pelas empresas nas duas vertentes de capital (terceiros e próprios). A literatura aponta várias métricas para se auferir tanto o custo de capital de terceiros quanto ao retorno exigido pelos sócios e acionistas das empresas. Em relação à última vertente, há apontamentos de que a escolha de uma medida empírica universalmente aceita para o custo de capital próprio, ainda permanece indefinida (ARTIACH; CLARKSON, 2011).

A métrica escolhida neste estudo considera o valor já repassado aos sócios e acionistas das empresas, por meio de dividendos e juros sobre o capital próprio. Tal métrica foi utilizada no estudo de Forti, Peixoto e Alves (2015), no entanto, optou-se por adotar como denominador o patrimônio líquido ao invés do ativo total, como no estudo original, considerando ser esta a parte do balanço patrimonial que representa efetivamente o capital próprio.

No Quadro 2 são apresentadas as variáveis independentes, utilizadas para testar as hipóteses propostas. 
Quadro 2 - Variáveis Independentes

\begin{tabular}{|c|c|c|c|}
\hline Descrição & Métrica & Fonte & Autores de base \\
\hline $\begin{array}{l}\text { Nível de evidenciação } \\
\text { socioambiental (NES) }\end{array}$ & $\begin{array}{l}\text { Número de itens atendidos } \\
\text { em relação ao número total } \\
\text { de itens da estrutura do IIRC } \\
(2015)\end{array}$ & $\begin{array}{l}\text { Relatórios de } \\
\text { Sustentabilidade }\end{array}$ & $\begin{array}{l}\text { Frías-Aceituno, } \\
\text { Rodríguez-Ariza e } \\
\text { García-Sánchez (2013); } \\
\text { Michaels e Gruning } \\
\text { (2017); Li e Liu (2018). }\end{array}$ \\
\hline $\begin{array}{l}\text { Setores de alto } \\
\text { impacto ambiental } \\
\text { (IMPACTO) }\end{array}$ & $\begin{array}{l}\text { Variável dummy, sendo } 1 \\
\text { para empresas constantes } \\
\text { nos setores de alto impacto } \\
\text { ambiental, conforme Lei } \\
\begin{array}{l}10.165 / 2000 \text { e } 0 \text { para as } \\
\text { demais. }\end{array}\end{array}$ & $\begin{array}{l}\text { Anexo VIII da Lei } \\
10.165 / 2000\end{array}$ & $\begin{array}{l}\text { Fernandes }(2012) \\
\text { Li e Liu }(2018)\end{array}$ \\
\hline NES x IMPACTO & \multicolumn{3}{|c|}{$\begin{array}{l}\text { Variável moderadora entre nível de evidenciação socioambiental x setores de } \\
\text { alto impacto ambiental }\end{array}$} \\
\hline $\begin{array}{c}\text { Conexões Políticas } \\
\text { por Participação } \\
\text { Acionária } \\
\text { (CON_PART) }\end{array}$ & $\begin{array}{c}\text { Havia participação } \\
\text { acionária de político ou do } \\
\text { governo de forma direta ou } \\
\text { indireta no ano de } 2014 \text { : } \\
\quad \text { Sim }=1 \text { Não=0 }\end{array}$ & $\begin{array}{l}\text { Formulário de } \\
\text { Referência }\end{array}$ & $\begin{array}{l}\text { Boubakri et al. (2012); } \\
\text { Tee (2018). }\end{array}$ \\
\hline NES x CON_PART & \multicolumn{3}{|c|}{$\begin{array}{l}\text { Variável moderadora entre nível de evidenciação socioambiental x empresas } \\
\text { conectadas politicamente por meio de participação acionária }\end{array}$} \\
\hline $\begin{array}{l}\text { Conexões Políticas } \\
\text { por Doações a } \\
\text { campanhas eleitorais } \\
\text { (CON_DOA) }\end{array}$ & $\begin{array}{l}\text { A companhia realizou } \\
\text { doação para campanha } \\
\text { eleitoral no ano de } 2014 \text { : } \\
\text { Sim }=1 \text { Não }=0\end{array}$ & $\begin{array}{c}\text { Sítio: } \\
\text { www.asclaras.org.br }\end{array}$ & $\begin{array}{l}\text { Camilo, Marcon e } \\
\text { Bandeira-de-Mello } \\
\text { (2012); Macedo, Silva e } \\
\text { Machado (2015); } \\
\text { Pinheiro, Luca e } \\
\text { Vasconcelos (2016). }\end{array}$ \\
\hline NES x CON_DOA & \multicolumn{3}{|c|}{$\begin{array}{l}\text { Variável moderadora entre nível de evidenciação socioambiental x empresas } \\
\text { conectadas politicamente por meio de doações a campanhas eleitorais }\end{array}$} \\
\hline
\end{tabular}

Fonte: elaboração própria.

Todas as variáveis foram calculadas com base no ano de 2017, exceto o nível de evidenciação socioambiental e as conexões políticas pela doação de campanha. Em relação ao nível de evidenciação socioambiental, adotou-se o ano de 2016, pois se acredita que o efeito será refletido no custo de capital das empresas nos períodos posteriores. Uma das explicações para este efeito deve-se a não obrigatoriedade de divulgação dos relatórios de sustentabilidade e a pouca exigência por prazos, fazendo com que as empresas disponibilizem os relatórios no segundo semestre do ano seguinte (ALMEIDA; SANTOS, 2014).

Quanto às conexões políticas, as empresas ao firmarem vínculos com o governo possuem certa expectativa de retorno posterior, como se fizessem um investimento (CAMILO; MARCON; BANDEIRA DE MELLO, 2012; PINHEIRO; LUCA; VASCONCELOS, 2016). Neste estudo, foram identificadas as empresas que possuíam conexões políticas firmadas no ano de 2014 (último pleito com doações permitidas) pelas doações financeiras de empresas a 
políticos e, também por meio da participação acionária do governo na estrutura de propriedade das firmas em 2017, a fim de averiguar o efeito destes vínculos políticos no custo de capital.

Para se auferir o nível de evidenciação socioambiental (Quadro 2), procedeu-se com análise dos relatórios de sustentabilidade, referente ao ano de 2016 e divulgados nos websites das empresas até dezembro de 2017, período em que foi realizada a coleta dos demonstrativos. A apuração do índice de evidenciação considerou uma lista de verificação composta por 31 itens, divididos em sete grandes áreas de atuação: (i) modelo empresarial e organizacional; (ii) contexto, riscos e oportunidades; (iii) objetivos estratégicos e estratégias; (iv) governança corporativa e políticas de remunerações; (v) comportamento, desempenho e criação de valor: financeiro, social e ambiental; (vi) perspectiva futura; e (vii) descrição dos indicadores quantitativos-chave de desempenho e risco analisados: eficiência econômica, ambiental e social, conforme utilizado por Frías-Aceituno, Rodríguez-Ariza e García-Sánchez (2013).

Para obtenção do nível de evidenciação socioambiental (NES), considerou-se a presença ou não da informação requerida no relatório. Assim, o item recebeu 1 (um) ponto se evidenciado e, caso contrário, atribuiu-se 0 (zero). Para cada item analisado, consideraram-se três tipos de informação: qualitativa, quantitativa e monetária. Desta maneira, cada item poderia receber até 3 (três) pontos, de acordo com a natureza da informação divulgada. Como a lista de verificação contém 31 itens, se a empresa informasse todos os requisitos, receberia até 93 pontos (31 pontos para qualitativo, 31 pontos para quantitativo e 31 pontos para monetário).

No Quadro 3, são expostas as variáveis de controle, as respectivas métricas utilizadas, a fonte de coleta e autores que já estudaram sua relação com o custo de capital das empresas.

Quadro 3 - Variáveis de Controle

\begin{tabular}{|c|c|c|c|}
\hline Descrição & Métrica & Fonte & Autores de base \\
\hline $\begin{array}{l}\text { Turnover } \\
\text { (TURN) }\end{array}$ & $\begin{array}{l}\frac{\text { Volume de ações negociadas por empresa* }^{*}}{\text { Média anual do Total de Ações negociadas na B3 }} \\
\text { *excluídas Ações em Tesouraria }\end{array}$ & $\begin{array}{l}\text { Banco de dados } \\
\text { Economatica e } \\
\text { Site Uol } \\
\text { Economia }\end{array}$ & Costi e Soares (2014). \\
\hline $\begin{array}{l}\text { Tamanho } \\
\text { (TAM) }\end{array}$ & $\begin{array}{l}\text { Logaritmo natural do valor contábil do } \\
\text { ativo total no final do período. }\end{array}$ & & $\begin{array}{l}\text { Fernandes } \\
\text { Martínez-Ferrero e García- } \\
\text { Sánchez (2017); Fonseka, } \\
\text { Rajapakse e Richardson } \\
(2018) \text {. }\end{array}$ \\
\hline $\begin{array}{l}\text { Retorno sobre o } \\
\text { Ativo (ROA) }\end{array}$ & $\frac{\text { Lucro Líquido }}{\text { Ativo Total }}$ & $\begin{array}{l}\text { Banco de dados } \\
\text { Economatica }\end{array}$ & $\begin{array}{l}\text { Peixoto et al. (2016); Tee } \\
\text { (2018); Fonseka, Rajapakse } \\
\text { e Richardson (2018). }\end{array}$ \\
\hline
\end{tabular}

(CONTINUA) 
(CONTINUAÇÃO)

\begin{tabular}{|c|c|c|c|}
\hline $\begin{array}{c}\text { Liquidez } \\
\text { Corrente (LC) }\end{array}$ & $\frac{\text { Ativo Circulante }}{\text { Passivo Circulante }}$ & & $\begin{array}{l}\text { Mansi; Maxwell; Miller } \\
\text { (2011); Peixoto et al. } \\
\text { (2016); Tee (2018). }\end{array}$ \\
\hline $\begin{array}{l}\text { Market-to-Book } \\
\text { (MTB) }\end{array}$ & $\frac{\text { Valor de Mercado }}{\text { Valor Contábil do Patrimônio Líquido }}$ & & $\begin{array}{l}\text { Fonseka, Rajapakse e } \\
\text { Richardson (2018); Liu e } \\
\text { Villiers (2011); Martínez- } \\
\text { Ferrero e García-Sánchez } \\
(2017) \text {; }\end{array}$ \\
\hline $\begin{array}{l}\text { Listagem em } \\
\text { Bolsa } \\
\text { Estrangeira } \\
\quad(\text { EST })\end{array}$ & $\begin{array}{l}\text { Variável dummy, sendo } 1 \text { para empresas } \\
\text { com negociações de ações nas bolsas } \\
\text { BCBA, BMV e NYSE e } 0 \text { para as demais. }\end{array}$ & & Gonçalves et al. (2013) \\
\hline $\begin{array}{l}\text { Auditoria } \\
\text { (AUD) }\end{array}$ & $\begin{array}{l}\text { Variável dummy, sendo } 1 \text { para empresa } \\
\text { auditada por big four, e } 0 \text { para as demais }\end{array}$ & $\begin{array}{l}\text { Formulário de } \\
\text { Referência }\end{array}$ & $\begin{array}{l}\text { Al-Hadi (2017); Bliss; Gul } \\
\text { (2012); Li e Liu (2018); }\end{array}$ \\
\hline $\begin{array}{l}\text { Nível } \\
\text { Governança } \\
\text { Corporativa } \\
\text { (NGC) }\end{array}$ & $\begin{array}{l}\text { Variável dummy, sendo } 1 \text { para empresas } \\
\text { com níveis diferenciados de governança } \\
\text { corporativa (Novo Mercado, Nível } 1 \text { e } \\
\text { Nível 2) e } 0 \text { para as demais. }\end{array}$ & Site da B3 & $\begin{array}{l}\text { Fernandes (2012); Li e Liu } \\
\text { (2018). }\end{array}$ \\
\hline
\end{tabular}

Fonte: elaboração própria.

As variáveis de controle (Quadro 3), também podem influenciar no custo de capital:

a) Turnover: considerada como uma proxy de risco, tendo em vista que proporciona informações de quão subvalorizada ou supervalorizada as ações se encontram. A expectativa é de que as organizações com altos índices de turnover tendem a ter baixo custo de capital de terceiros e aumento no custo de capital próprio (COSTI; SOARES, 2014).

b) Tamanho: empresas maiores geralmente estão associadas a menores riscos pela diversificação e amplitude de suas atividades, dessa forma enseja-se uma relação negativa no que tange ao tamanho e o custo de capital de terceiros e positiva com o custo de capital próprio (FERNANDES, 2012; FONSEKA; RAJAPAKSE; RICHARDSON, 2018; MARTÍNEZFERRERO; GARCÍA-SÁNCHEZ, 2017).

c) ROA: empresas com maior ROA captam recursos com menor custo de capital de terceiros, tendo em vista que o risco é menor, esperando-se uma relação negativa entre as variáveis. Por outro lado, tais empresas geram maior retorno aos acionistas, aumentando o CCP (FONSEKA; RAJAPAKSE; RICHARDSON, 2018; PEIXOTO et al., 2016; TEE, 2018).

d) Liquidez Corrente: quanto maior o índice maior a capacidade de cumprimento de suas obrigações e distribuição de lucros aos acionistas, esperando-se uma associação negativa com o custo de capital de terceiros e positiva com o custo de capital próprio (TEE, 2018; MANSI; MAXWELL; MILLER, 2011; PEIXOTO et al., 2016). 
e) Market-to-Book: as empresas em ascensão tendem a cumprir com suas obrigações no prazo previsto e efetuar maior distribuição de dividendos aos investidores, sendo assim espera-se uma relação negativa com o custo de capital de terceiros e positiva com o capital próprio (FONSEKA; RAJAPAKSE; RICHARDSON, 2018; LIU; VILLIERS, 2011; MARTÍNEZFERRERO; GARCÍA-SÁNCHEZ, 2017).

f) Listagem em Bolsa Estrangeira: indica que tais empresas, ao buscar a sua consolidação em mercados internacionais, são consideradas com melhores práticas gerenciais, menor assimetria informacional, o que, diminuiria o risco percebido pelo mercado financeiro e, portanto, acentuação da relação negativa com o custo de capital de terceiros e positiva com o capital próprio (GONÇALVES et al., 2013).

g) Auditoria: permite monitorar o comportamento oportunista da gestão, no qual a informação financeira confiável e transparente que emana de maior qualidade de auditoria auxilia os investidores e credores prever fidedignamente os fluxos de caixa futuros, reduz a assimetria das informações e diminui as incertezas de mercado e consequentemente os custos (AL-HADI et al., 2017; BLISS; GUL, 2012; LI; LIU, 2018).

h) Nível Governança Corporativa: os princípios da transparência e prestação de contas da governança corporativa possibilitam a redução na assimetria informacional, esperando-se uma associação negativa entre as proxys (FERNANDES, 2012; LI; LIU, 2018).

Dessa forma, para verificar a influência das variáveis independentes e de controle sobre o custo de capital das empresas, utilizaram-se os seguintes modelos de regressão, considerandose separadamente o capital próprio e de terceiros:

$$
\begin{aligned}
& \mathrm{CC}_{\mathrm{it}}=\beta_{o}+\beta_{1} \mathrm{NES}_{i t}+\beta_{2} I_{M P A C T O}+\beta_{3} C O N_{-} P A R T_{i t}+\beta_{4} C O N_{-} D O A_{i t}+ \\
& \beta_{5} T A M_{i t}+\beta_{6} R O A_{i t}+\beta_{7} L C_{i t}+\beta_{8} T U R N_{i t}+\beta_{9} M T B_{i t}+\beta_{10} E S T_{i t}+\beta_{11} A U D_{i t}+ \\
& \beta_{12} N G C_{i t}+\varepsilon(1) \boldsymbol{H}_{1} \boldsymbol{H}_{2}
\end{aligned}
$$

$$
\begin{gathered}
\mathrm{CC}_{\mathrm{it}}=\beta_{o}+\beta_{1} \mathrm{NES}_{i t}+\beta_{2} \text { IMPACTO }_{i t}+\beta_{3} \text { NESXIMPACTO }_{i t}+\beta_{4} \text { TAM }_{i t}+ \\
\beta_{5} \text { ROA }_{i t}+\beta_{6} L C_{i t}+\beta_{7} \text { TURN }_{i t}+\beta_{8} \text { MTB }_{i t}+\beta_{9} E_{\text {SST }}+\beta_{10} A U D_{i t}+\beta_{11} N G C_{i t}+\varepsilon(2) \boldsymbol{H}_{3}
\end{gathered}
$$

$$
\begin{gathered}
\mathrm{CC}_{\mathrm{it}}=\beta_{o}+\beta_{1} \mathrm{NES}_{i t}+\beta_{2} \text { CON_PART }_{i t}+\beta_{3} N E S x C O N_{-} P A R T_{i t}+\beta_{4} T A M_{i t}+ \\
\beta_{5} R O A_{i t}+\beta_{6} L C_{i t}+\beta_{7} T U R N_{i t}+\beta_{8} M_{T} B_{i t}+\beta_{9} E S T_{i t}+\beta_{10} A U D_{i t}+\beta_{11} N G C_{i t}+\varepsilon(3) \boldsymbol{H}_{3}
\end{gathered}
$$




$$
\begin{gathered}
\mathrm{CC}_{\mathrm{it}}=\beta_{o}+\beta_{1} \mathrm{NES}_{i t}+\beta_{2} \text { CON_DOA }_{i t}+\beta_{3} N E S x C_{-} O N_{-} D O A_{i t}+\beta_{4} T A M_{i t}+ \\
\beta_{5} R O A_{i t}+\beta_{6} L C_{i t}+\beta_{7} T_{U R N_{i t}}+\beta_{8} M T B_{i t}+\beta_{9} E S T_{i t}+\beta_{10} A U D_{i t}+\beta_{11} N G C_{i t}+\varepsilon(4) \boldsymbol{H}_{3}
\end{gathered}
$$

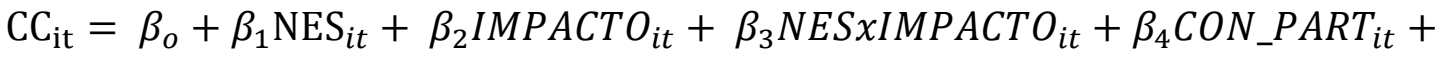

$$
\begin{aligned}
& \beta_{5} N E S x C O N_{-} P A R T_{i t}+\beta_{6} C O N_{-} D O A_{i t}+\beta_{7} N E S x C O N_{-} D O A_{i t}+\beta_{8} T A M_{i t}+\beta_{9} R O A_{i t}+ \\
& \beta_{10} L C_{i t}+\beta_{11} T_{U R N_{i t}}+\beta_{12} M T B_{i t}+\beta_{13} E S T_{i t}+\beta_{14} A U D_{i t}+\beta_{15} N G C_{i t}+\varepsilon(5) \boldsymbol{H}_{3}
\end{aligned}
$$

Para assegurar a confiabilidade dos resultados, foram atendidos os pressupostos da regressão linear múltipla, conforme indicado por Corrar, Paulo e Dias Filho (2014), incluindo: multicolinearidade (teste VIF); autocorrelação de resíduos (teste Durbin-Watson); normalidade, embora não atendido o teste Kolmogorov-Smirnov, admite-se a premissa de normalidade para as amostras maiores de 100 observações com base no Teorema do Limite Central (GUJARATI, 2006); e à homocedasticidade (teste Pesáran-Pesáran), em que identificou-se problema de heterocedasticidade nos dados, solucionado pela correção de White no software STATA.

\section{ANÁLISE E DISCUSSÃO DOS RESULTADOS}

\subsection{Análise dos resultados}

Na Tabela 1 consta a estatística descritiva das variáveis quantitativas. Ao se comparar as duas vertentes do custo de capital, pode-se inferir que as empresas analisadas têm uma média maior de custo de capital com fontes externas do que o custo com seus acionistas. Os resultados divergem de Ballestero, Nogueira e Vitorino Filho (2016) que analisaram o impacto da evidenciação voluntária sobre o custo de capital das empresas brasileiras no período de 2008 a 2012 e identificaram o custo de capital próprio maior do que o de terceiros, contudo, ressaltase que a métrica para avaliar o capital próprio foi distinta desse estudo.

Tabela 1 - Estatística descritiva

\begin{tabular}{l|c|c|c|c|c}
\hline Variáveis & N & Mínimo & Máximo & Média & Desvio-Padrão \\
\hline CCP (Custo de Capital Próprio) & 275 & 0,000 & 0,477 & 0,041 & 0,077 \\
CCT (Custo de Capital de Terceiros) & 275 & 0,000 & 6,257 & 0,336 & 0,674 \\
NES (Evidenciação Socioambiental) & 275 & 0,000 & 0,817 & 0,199 & 0,270 \\
TAM (Tamanho) & 275 & 4,195 & 8,920 & 6,425 & 0,815 \\
ROA (Retorno sobre o Ativo) & 275 & $-1,602$ & 0,543 & $-0,013$ & 0,203 \\
LC (Liquidez Corrente) & 275 & 0,005 & 8,243 & 1,529 & 1,146 \\
& & & & & (CONTINUA)
\end{tabular}


INFLUÊNCIA DAS CONEXÕES POLÍTICAS E DA EVIDENCIAÇÃO SOCIOAMBIENTAL NO CUSTO DE CAPITAL

\begin{tabular}{l|c|c|c|c|c} 
(CONTINUAÇÃO) & 275 & 0,000 & 68,929 & 0,746 & 5,742 \\
TURN (Turnover) & 275 & $-1,821$ & 22,033 & 1,544 & 2,318 \\
MTB (Market-to-Book) &
\end{tabular}

Fonte: elaboração própria.

Quanto ao nível de evidenciação socioambiental (NES), constante na Tabela 1, a média de divulgação nos relatórios de sustentabilidade feita pelas empresas foi de aproximadamente 19,90\%. Vale destacar que das 275 empresas analisadas, 102 empresas divulgaram seus relatórios nos websites durante o período de coleta da pesquisa. Diante de pesquisas anteriores é possível auferir que as corporações estão cada vez mais preocupadas em divulgar suas ações socioambientais. Rover (2013) aborda que no ano de 2008 apenas 55 organizações evidenciavam esse tipo de informação, já em 2010 eram 91. Denota-se, portanto, um crescimento no número de empresas que se engajam na evidenciação socioambiental. A Tabela 2 apresenta a frequência das variáveis categóricas do estudo.

Tabela 2 - Análise de Frequência

\begin{tabular}{|c|c|c|c|c|c|}
\hline Variável & $\mathbf{N}$ & SIM & $\%$ & NÃO & $\%$ \\
\hline IMPACTO (Setores de Alto Impacto Ambiental) & 275 & 50 & 18,2 & 225 & 81,8 \\
\hline CON_PART (Conexões Políticas_Participação Acionária) & 275 & 25 & 9,1 & 250 & 90,9 \\
\hline CON_DOA (Conexões Políticas_Doações para Campanhas) & 275 & 52 & 18,9 & 223 & 81,1 \\
\hline EST (Listagem em Bolsa Estrangeira) & 275 & 16 & 5,8 & 259 & 94,2 \\
\hline AUD (Auditoria Big Four) & 275 & 217 & 78,9 & 58 & 21,1 \\
\hline NGC (Nível de Governança Corporativa) & 275 & 143 & 52 & 132 & 48 \\
\hline
\end{tabular}

Fonte: elaboração própria.

Das 275 empresas selecionadas para compor a amostra da pesquisa, 50 pertencem aos setores de alto impacto ambiental (IMPACTO); 16 possuem negociação de ações em bolsas estrangeiras (EST); 143 constam em níveis diferenciados de governança corporativa; 217 são auditadas por uma firma big four (AUD). Quanto às conexões políticas, 25 empresas estavam vinculadas ao governo por meio da estrutura de propriedade e 52 realizaram doações para campanhas eleitorais no ano de 2014.

Adiante, apresentam-se as análises das relações propostas no objetivo de pesquisa. $\mathrm{Na}$

Tabela 3, constam as regressões em que a variável dependente é o custo de capital próprio.

Tabela 3 - Resultados das regressões dos modelos de custo de capital próprio

\begin{tabular}{l|c|c|c|c|c}
\hline \multicolumn{5}{c}{ Variável dependente: CCP (Custo de Capital Próprio) } \\
\hline \multicolumn{1}{c|}{ Variáveis } & Modelo 1 & Modelo 2 & Modelo 3 & Modelo 4 & Modelo 5 \\
\hline (Constante) & $-0,013$ & $-0,002$ & 0,004 & $-0,002$ & 0,003 \\
NES & 0,032 & 0,029 & $\mathbf{0 , 0 4 5} * *$ & 0,034 & $\mathbf{0 , 0 5 1}$ \\
IMPACTO & $-0,006$ & $-0,007$ & & & $-0,007$ \\
NES x IMPACTO & & 0,011 & & & 0,009 \\
CON_PART & $\mathbf{- 0 , 0 2 8 * *}$ & & 0,023 & & 0,018 \\
NES x CON_PART & & & $\mathbf{- 0 , 1 3 5 * * *}$ & & $\mathbf{- 0 , 1 3 9 * * *}$ \\
& & & & & (CONTINUA)
\end{tabular}




\begin{tabular}{|c|c|c|c|c|c|}
\hline (CONTINUAÇÃO) & & & & & \\
\hline CON_DOA & $\mathbf{- 0 , 0 1 8} * * *$ & & & $-0,012$ & $-0,011$ \\
\hline NES x CON_DOA & & & & $-0,017$ & $-0,037$ \\
\hline TAM & 0,005 & 0,003 & 0,001 & 0,003 & 0,002 \\
\hline ROA & $\mathbf{0 , 0 5 7 * * *}$ & $0,059 * * *$ & $\mathbf{0 , 0 6 0 * * *}$ & $\mathbf{0 , 0 5 8} * * *$ & $0,057 * * *$ \\
\hline LC & 0,002 & 0,001 & 0,000 & 0,001 & 0,001 \\
\hline TURN & 0,002 & 0,002 & 0,002 & 0,002 & 0,002 \\
\hline МТB & 0,006* & $0,007 *$ & 0,006* & $0,007 *$ & $0,006 *$ \\
\hline EST & $-0,017$ & $-0,020 *$ & $-0,018$ & $-0,020 *$ & $-0,016$ \\
\hline AUD & $0,025 * *$ & $0,028 * * *$ & $\mathbf{0 , 0 2 9} * * *$ & $\mathbf{0 , 0 2 7} * * *$ & $0,026 * * *$ \\
\hline NGC & $-0,021 * *$ & $-0,025 * *$ & $-0,022 * *$ & $-0,021 * *$ & $-0,019 *$ \\
\hline $\mathrm{R}^{2}$ ajustado & 0,1407 & 0,1287 & 0,1504 & 0,1342 & 0,1485 \\
\hline F-ANOVA & $4,739 * * *$ & $4,678 * * *$ & $5,410 * * *$ & $4,860 * * *$ & $4,186 * * *$ \\
\hline Durbin Watson & 2,088 & 2,060 & 2,077 & 2,067 & 2,097 \\
\hline VIF/Tolerance & $<3$ & $<3$ & $<4$ & $<3$ & $<4$ \\
\hline
\end{tabular}

Fonte: elaboração própria.

*** Significativo a 1\%; ** Significativo a 5\%; * Significativo a 10\% (em negrito na Tabela 3 ).

Dentre os fatores abordados, aqueles que contribuíram de forma positiva e estatisticamente significativa para o aumento do CCP, nos diversos modelos, têm-se: NES, ROA, MTB e AUD. Esse resultado corrobora com os indícios teóricos ao apontar que a evidenciação socioambiental traz retornos mais satisfatórios para o capital investido pelos acionistas. Do mesmo modo, encontra-se resultados que melhoram o nível de retorno do investimento de acionistas com relação as empresas com maior retorno sobre os ativos, maior market-to-book e com auditoria big four.

Por outro lado, as variáveis CON_PART, NESxCON_PART, EST e NGC demonstraram exercer influência negativa e estatisticamente significativa sobre o CCP. Os achados são condizentes com os argumentos empíricos de que as conexões políticas afetam negativamente o custo de capital próprio, piorando o retorno sobre o capital investido pelos acionistas. Além disso, pode-se considerar que as conexões políticas moderam negativamente a relação entre evidenciação socioambiental e o custo de capital próprio. Por fim, resultados adicionais indicam que a listagem estrangeira e os níveis de governança corporativa têm prejudicado o custo de capital próprio.

A Tabela 4 apresenta as regressões que consideram o custo de capital de terceiros como variável dependente.

Tabela 4 - Resultados das regressões dos modelos de custo do capital de terceiros

\begin{tabular}{l|c|c|c|c|c}
\hline \multicolumn{7}{c}{ Variável dependente: CCT (Custo de Capital de Terceiros) } \\
\hline \multicolumn{1}{c}{ Variáveis } & Modelo 1 & Modelo 2 & Modelo 3 & Modelo 4 & Modelo 5 \\
\hline (Constante) & $\mathbf{1 , 7 9 8}_{* * *}^{*}$ & $\mathbf{1 , 7 5 9} * * *$ & $\mathbf{1 , 8 0 6}^{* * *}$ & $\mathbf{1 , 7 2 8}_{* * *}^{*}$ & $\mathbf{1 , 8 1 2 * * *}$ \\
NES & $\mathbf{0 , 2 9 3}^{* *}$ & $\mathbf{0 , 2 7 8 * *}$ & $\mathbf{0 , 3 0 0 * *}$ & $\mathbf{0 , 3 8 9 * *}$ & $\mathbf{0 , 3 7 6 * * *}$ \\
IMPACTO & $-0,070$ & $-0,099$ & & & $-0,101$
\end{tabular}

(CONTINUA) 
(CONTINUAÇÃO)

\begin{tabular}{l|c|c|c|c|c} 
NES x IMPACTO & & 0,125 & & & 0,177 \\
CON_PART & $\mathbf{0 , 1 2 4} *$ & & 0,143 & & 0,179 \\
NES x CON_PART & & & $-0,110$ & & $-0,199$ \\
CON_DOA & 0,117 & & & 0,188 & 0,206 \\
NES x CON_DOA & & & & $-0,479$ & $-0,477$ \\
TAM & $\mathbf{- 0 , 2 3 9 * * *}$ & $\mathbf{- 0 , 2 2 9 * * *}$ & $\mathbf{- 0 , 2 4 2 * * *}$ & $\mathbf{- 0 , 2 2 9} * * *$ & $\mathbf{- 0 , 2 4 2} * * *$ \\
ROA & $-0,930$ & $\mathbf{- 0 , 9 4 2} *$ & $\mathbf{- 0 , 9 3 6 *}$ & $-0,922$ & $-0,930$ \\
LC & $\mathbf{0 , 0 7 1 *}$ & $\mathbf{0 , 0 8 0}$ & $\mathbf{0 , 0 7 3} *$ & $\mathbf{0 , 0 7 0 *}$ & $\mathbf{0 , 0 7 1 *}$ \\
TURN & $-0,002$ & $-0,001$ & $-0,002$ & $-0,002$ & $-0,002$ \\
MTB & $-0,002$ & $-0,004$ & $-0,001$ & $-0,003$ & $-0,002$ \\
EST & 0,148 & 0,160 & 0,143 & 0,144 & 0,148 \\
AUD & $-0,103$ & $-0,114$ & $-0,096$ & $-0,125$ & $-0,119$ \\
NGC & $-0,098$ & $-0,082$ & $-0,077$ & $-0,076$ & $-0,087$ \\
\hline R 2ajustado & 0,1650 & 0,1627 & 0,1627 & 0,1692 & 0,1613 \\
F-ANOVA & $5,513 * * *$ & $5,839 * * *$ & $5,839 * * *$ & $6,074 * * *$ & $4,514 * * *$ \\
Durbin Watson & 2,076 & 2,080 & 2,070 & 2,051 & 2,074 \\
VIF & $<3$ & $<3$ & $<4$ & $<3$ & $<4$ \\
\hline
\end{tabular}

Fonte: elaboração própria.

*** Significativo a 1\%; ** Significativo a 5\%; * Significativo a 10\% (em negrito na Tabela 4).

Dentre os fatores abordados, aqueles que contribuíram de forma positiva e estatisticamente significativa para o aumento do CCT, nos diversos modelos, têm-se: NES, CON_PART e LC. Os resultados indicam que, empresas com maior nível de evidenciação socioambiental possuem maior custo de capital de terceiros. Este achado condiz com os argumentos de que, as instituições financeiras observam os riscos que estão divulgados nos relatórios de sustentabilidade, aumentando as taxas de juros de financiamento destes negócios.

Além disso, as conexões políticas aumentam o CCT. Este achado comprova que as instituições financeiras percebem um risco no financiamento destas organizações e, por isso, aplicam taxas de juros mais elevadas ao financiamento/empréstimo. Ou até mesmo, pode ser uma questão de oportunidade por parte das instituições bancárias, ao perceber que pode haver uma sobra de recursos financeiros nas empresas com conexões políticas e, assim, como uma maneira de arrecadar maior recurso, aplicam juros mais altos.

As variáveis TAM e ROA demonstraram exercer influência negativa e estatisticamente significativa no CCT. Desse modo, afirma-se que as empresas maiores e com maior retorno sobre os investimentos conseguem captar recursos de terceiros com taxas de juros menores, comprovando-se os argumentos teóricos já apontados. 


\subsection{Discussão dos resultados}

No Quadro 4 são confrontados os sinais esperados na formulação das hipóteses com os resultados encontrados, com base nos modelos de regressão.

Quadro 4 - Resumo dos resultados e hipóteses da pesquisa

\begin{tabular}{|c|c|c|c|c|}
\hline \multirow{2}{*}{ Hipóteses } & \multicolumn{2}{|c|}{ Custo de Capital Próprio } & \multicolumn{2}{c|}{ Custo de Capital de Terceiros } \\
\cline { 2 - 5 } & Sinal Esperado & Sinal Encontrado & Sinal Esperado & Sinal Encontrado \\
\hline $\mathrm{H}_{1}$ & + & $+^{*}$ & + & $+^{*}$ \\
\hline $\mathrm{H}_{2}$ & - & $-*$ & + & $+^{*}$ \\
\hline $\mathrm{H}_{3}$ & - & $-*$ & - & - \\
\hline
\end{tabular}

Fonte: elaboração própria.

*Significância estatística.

Ao se considerar a $\mathrm{H}_{1}$ (as empresas com maior nível de evidenciação socioambiental aumentam (aumentam) o custo de capital próprio (custo de capital de terceiros)), nota-se que os sinais positivos no CCP e no CCT obtidos nas evidências empíricas sugerem aceitar a $\mathrm{H}_{1}$.

Atribui-se duas possíveis razões para este achado, com base no estudo de Liu e Villiers (2011): (i) informações negativas e custos atrelados às variáveis da sustentabilidade podem contribuir para que os acionistas exijam maior retorno devido à consciência do risco, favorecendo o aumento de capital; (ii) os acionistas e investidores podem considerar que os custos e desembolsos envolvidos para disseminação das informações relacionadas à postura socioambiental das empresas, possam superar seus potenciais benefícios. Dessa maneira, o retorno exigido pelo capital investido, tende a ser superior para as empresas que divulgam estas informações ou que possuem um elevado nível de evidenciação socioambiental.

Além disso, confirmam-se as evidências de que o nível elevado de divulgação socioambiental aumenta a liquidez das ações e a remuneração sobre o capital próprio dos acionistas (ROVER, 2013). Por fim, pode-se inferir que as empresas com maior nível de evidenciação socioambiental são percebidas de maneira diferente pelo mercado, o qual reage de maneira positiva sobre o impacto no preço das ações. Isso trará maior retorno para o capital investido pelos acionistas, corroborando Deegan e Rankin (1996), Berthelot, Cormier e Magnan (2003), Lorraine et al. (2004), Iudícibus e Lopes (2004), Lopes e Martins (2005), Ribeiro, Nascimento e Bellen (2009) e Ghoul et al. (2011).

Quanto ao CCT, a influência positiva do nível de evidenciação socioambiental foi ainda mais pronunciada, possibilitando afirmar que a divulgação de tais informações causa um aumento no custo. Os bancos e instituições de crédito avaliam a concessão de recursos mediante 
dados quantitativos e de natureza financeira, aspectos estes facilmente verificáveis. Contudo, as análises das informações socioambientais, podem resultar previsões mais precisas quanto aos riscos, que não são identificáveis nos relatórios convencionais (HOEPNER et al., 2016). Este resultado confirma a evidência de que as instituições financeiras se utilizam das informações socioambientais para avaliar o risco atrelado ao negócio de crédito e cobrar com isso taxas de juros mais elevadas. Portanto, confirmam-se as evidências de Sharfman e Fernando (2008), Rover, Borba e Murcia (2009), Reverte (2012) e Li e Liu (2018).

Ademais, empresas com maiores níveis de divulgação de RSC, possuem maior facilidade em obter recursos, se comparadas com aquelas com menor evidenciação destas informações, por conta da redução da assimetria informacional e melhora da confiança dos credores (ALMEIDA; SANTOS, 2016; PEIXOTO et al., 2016). Com acesso facilitado, tais empresas podem captar uma quantidade maior de recursos, elevando seus níveis de endividamento. Por consequência, o aumento da captação de recursos, tende a aumentar a percepção de risco e assim majorar o CCT. Caberia aqui, investigações voltadas a averiguar o efeito da evidenciação socioambiental em empresas com maiores e menores graus de endividamento, analisando um possível reflexo nesta vertente.

Quanto a $\mathrm{H}_{2}$ (as empresas com conexões políticas reduzem (aumentam) o custo de capital próprio (custo de capital de receiros)), nota-se sinal negativo no CCP e positivo no CCT, as evidências sugerem a aceitação desta hipótese. Os resultados indicam que as conexões políticas reduzem a remuneração do capital próprio. Boubakri et al. (2012) sugerem que os elos políticos são garantias implícitas de socorro corporativo e têm um impacto significativo sobre o CCP. Nesse sentido, sob a ótica dos acionistas, os benefícios e a segurança trazidos pelo governo, podem ser indícios de menor risco, fazendo com que, o retorno exigido seja menor.

Infere-se que, as empresas com conexões políticas são ineficientes na aplicação dos recursos, por apresentarem menor remuneração de capital dos acionistas, corroborando Li e Liu (2018). Tal ineficiência está atrelada à necessidade de satisfazer interesses políticos por parte destas organizações, acarretando conflitos na competividade e desempenho organizacional (JACKOWICZ; KOZLOWSKI; MIELCARZ, 2014; LIEDONG; RAJWANI, 2017).

Ademais, os resultados indicam que as empresas com conexões políticas apresentam influências positivas no custo de capital de terceiros. Embora não se observou significância estatística, nos demais modelos em que estavam inclusas, as duas métricas de conexões políticas 
(CON_PART e CON_DOA), também apresentaram coeficientes positivos em todos os casos, confirmando um indício de efeito positivo sobre a variável dependente.

Confirmam-se as evidências de Tee (2018), ao relatar que o clientelismo político pode trazer benefícios de acesso ao crédito para as organizações. Esta possibilidade pode estar propiciando, às empresas com conexões políticas, acesso maior as fontes de recursos externas, aumentando por consequência, o grau de endividamento e, em segundo momento, a percepção de risco por parte das instituições financeiras, as quais aplicam taxas de juros maiores sobre o crédito ofertado. Além disso, os resultados corroboram Borisova et al. (2015), ao demonstrar que as instituições financeiras têm uma visão de que as conexões políticas trazem malefícios para o desempenho e a eficiência das empresas.

Por fim, ao considerar a $\mathrm{H}_{3}$ (as conexões políticas afetam negativamente (positivamente)) a relação entre evidenciação socioambiental e o custo de capital próprio (custo de capital de terceiros), nota-se que as conexões políticas moderam negativamente a relação entre evidenciação socioambiental e o custo de capital próprio e, por outro lado, o efeito negativo sobre a relação entre evidenciação socioambiental e o custo de capital próprio não foi comprovada estatisticamente, aceitando-se parcialmente está hipótese.

Admite-se assim, que o nível de evidenciação socioambiental possui efeito negativo mais pronunciado em empresas conectadas politicamente com o governo, por meio da estrutura de propriedade, para a redução da remuneração destinada aos sócios e acionistas. Tal achado corrobora com evidências anteriores (LI; LIU, 2018) e uma das possíveis explicações, pauta-se no fato dos privilégios trazidos por estas organizações, a menor preocupação com as partes interessadas e a maior probabilidade de conflitos de agência entre gestores e acionistas. Sendo assim, mesmo que as empresas com conexões políticas estejam com alto nível de evidenciação socioambiental, isso não tem se refletido no retorno do capital investido pelos acionistas.

Tal condição pode favorecer o estabelecimento de estratégias corporativas (preventivas ou competitivas), antecipando o repasse informacional destas ações nos relatórios de sustentabilidade aos investidores e credores, que acabam tendo maior confiança na organização e exigindo um menor retorno pelo capital investido. A participação acionária do governo na estrutura de propriedade da empresa, caracteriza-se como o vínculo político mais forte e direto (WU et al., 2012), podendo oferecer maior pressão à companhia quanto à evidenciação de aspectos socioambientais. Tal efeito melhora a credibilidade e reputação empresarial, reduzindo o custo pelo investimento de capital, advindo dos acionistas e investidores. Os resultados 
INFLUÊNCIA DAS CONEXÕES POLÍTICAS E DA EVIDENCIAÇÃO SOCIOAMBIENTAL NO CUSTO DE CAPITAL

inclusivos em relação ao CCT, pelos coeficientes negativos percebidos, podem representar um indicativo para maior aprofundamento empírico no cenário empresarial e político brasileiro.

\section{CONSIDERAÇÕES FINAIS}

Como principal achado da pesquisa, pode-se constatar que a evidenciação socioambiental acarreta no aumento do retorno sobre o capital investido pelos acionistas e, por outro lado, taxas de juros maiores aplicadas na oferta de crédito pelas instituições financeiras. Quanto ao custo de capital próprio, atribui-se o resultado à percepção dos acionistas de que os custos envolvidos para evidenciar tais informações superam seus potenciais benefícios. Adicionalmente, o maior nível de informações socioambientais pode elevar a percepção de riscos, proporcionando um aumento no retorno exigido pelos investidores e acionistas.

Já em relação ao custo de capital de terceiros, o efeito da divulgação socioambiental pode propiciar um acesso facilitado na obtenção de empréstimos e financiamentos juntos a bancos e demais instituições financeiras. A elevação do endividamento, por sua vez, pode acarretar acréscimo na percepção de riscos e aumento do custo dos empréstimos.

De maneira geral, conclui-se que os financiadores do capital de terceiros não têm valorizado as práticas socioambientais na oferta do crédito. Por outro lado, percebe-se que os acionistas recebem maior retorno sobre os seus investimentos quando a empresa apresenta RSC pelas ações socioambientais. Este resultado indica que a evidenciação socioambiental traz maior retorno que se reflete na melhor remuneração do capital dos acionistas.

Quanto às conexões políticas, constatou-se a influência negativa da existência destes vínculos sobre o custo de capital próprio das empresas. O estabelecimento de relações firmadas com o governo, tanto pela estrutura de propriedade quanto por doações às campanhas eleitorais, pode repassar aos acionistas uma imagem de segurança frente aos riscos corporativos, impactando na redução do retorno exigido.

Porém, as conexões políticas estabelecidas pela participação do governo na estrutura de propriedade, provocaram aumento no custo de capital de terceiros. $\mathrm{O}$ acesso preferencial ao crédito proporcionado por tal condição, pode servir de incentivo para o uso de recursos externos para o financiamento de suas atividades. Ao elevar o grau de endividamento externo, estas organizações são tidas pelos credores com risco também maior, exigindo maior retorno financeiro por empréstimos e financiamentos concedidos. 
Quando observado o efeito da divulgação socioambiental aliado à possibilidade de a empresa manter conexões políticas, constatou-se uma redução no custo de capital próprio. Assim sendo, a redução da assimetria informacional entre a empresa conectada com o governo e o mercado, pode proporcionar uma tempestiva evidenciação socioambiental nos relatórios de sustentabilidade, criando certa sensação de segurança aos acionistas e investidores destas organizações. Além disso, a própria participação do governo na estrutura de propriedade da companhia, pode impulsionar um elevado repasse informacional de caráter socioambiental. Como consequência, tem-se uma redução no retorno exigido pelo aporte de capital próprio.

Nesta pesquisa, buscou-se averiguar o impacto da evidenciação socioambiental, considerando o custo de capital de terceiros e próprio conjuntamente, para que, de forma implícita, seja possível uma comparação das consequências que essa prática voluntária pode proporcionar às companhias. A verificação do efeito das conexões políticas sobre o custo de capital das empresas, também se apresenta adequada, admitindo a disseminação destas relações no contexto político e empresarial brasileiro. Porém, o principal diferencial do estudo consiste na análise conjunta, do reflexo da divulgação socioambiental e o estabelecimento de conexões políticas sobre o custo de capital, a qual se apresenta incipiente no contexto nacional.

Conclui-se que a conexão política exerce efeito positivo sobre o custo de capital próprio e maior evidência que a própria responsabilidade social corporativa (RSC) pela evidenciação socioambiental. Portanto, parece plausível assumir que as conexões políticas possuem força superior à divulgação voluntária de informações da RSC.

Os indicíos apontam que as conexões políticas pioram o retorno sobre os investimentos dos acionistas pela relação negativa com o custo de capital próprio e ainda geram aumento no custo de capital de terceiros. Ademais, o efeito moderador das conexões políticas na relação entre evidenciação socioambiental e o custo de capital próprio e de terceiros, prejudica a RSC pela evidenciação socioambiental na remuneração do capital dos acionistas (próprio). Sendo assim, a evidenciação socioambiental não tem efeito positivo sobre o custo de capital próprio quando associada às empresas com conexões políticas, fazendo assim, com que os acionistas tenham um menor retorno sobre o capital investido.

Comprova-se que as conexões políticas podem exercer efeito contrário na atuação dos mecanismos de GC, tendo em vista a piora no retorno dos investimentos de acionistas e no aumento do CCT. Conclui-se que as conexões políticas são prejudicionais aos acionistas e investidores e gera ineficiência da organização na captação de recursos de terceiros. Por outro 
lado, a evidenciação socioambiental é benéfica para o retorno dos acionistas, contudo, as instituições bancárias não observam os benefícios destes investimentos corporativos.

\section{AGRADECIMENTO}

Os autores agradecem ao Programa de Suporte à Pós-Graduação de Instituições Comunitárias de Educação Superior (PROSUC) - Coordenação de Aperfeiçoamento de Pessoal de Nível Superior (CAPES) e à Universidade Comunitária da Região de Chapecó UNOCHAPECÓ, pelo auxílio financeiro que permitiram a realização da pesquisa.

\section{REFERÊNCIAS}

AGUILERA, R. V.; RUPP, D. E. WILLIAMS, C. A.; GANAPATHI, J. Putting the S back in corporate social responsibility: A multilevel theory of social change in organizations. Academy of management review, v. 32, n. 3, p. 836-863, 2007.

AL-HADI, A.; HABIB, A.; AL-YAHYAEE, K.; EULAIWI, B. Joint audit, political connections and cost of debt capital. International Journal of Auditing, v. 21, n. 3, p. 249270, 2017.

ALMEIDA, M. A.; SANTOS, J. F. D. Disclosure voluntário de responsabilidade social corporativa das empresas listadas na BM\&FBovespa. Revista de Gestão Social e Ambiental, v. 8, n. 3, p. 69-88, 2014.

ALMEIDA, M. A.; SANTOS, J. F. D. Estrutura de Capital e Divulgação Voluntária de Informações de Responsabilidade Social Corporativa das Empresas Brasileiras. Revista de Ciências da Administração, v. 18, n. 45, p. 109-126, 2016.

ARTIACH, T. C.; CLARKSON, P. M. Disclosure, conservatism and the cost of equity capital: A review of the foundation literature. Accounting \& Finance, v. 51, n. 1, p. 2-49, 2011.

ASHLEY, P. A. Ética e Responsabilidade Social nos Negócios. $2^{\text {a }}$ ed. São Paulo: Saraiva, 2005.

BALleSterO, A.; NOGUEIRA, I. V.; VITORINO FILHO, V. A. Análise do nível de disclosure voluntário e o custo de capital das empresas brasileiras: no período de 2008 a 2012. Contabilidade, Gestão e Governança, v. 19, n. 3, p. 356-375, 2016. 
BARROS, C. M. E.; KOS, S.; R.; CONSONI, S.; COLAUTO, R.; D . A influência do disclosure voluntário no custo da dívida de financiamentos em empresas listadas na BMFBOVESPA. Revista Ambiente Contábil, v. 9, n. 2, p. 334-354, 2017.

BELKAOUI, A. The impact of the disclosure of the environmental effects of organizational behavior on the market. Financial Management, v. 5, n. 4, p. 26, 1976.

BERTHELOT, S.; CORMIER, D.; MAGNAN, M. Environmental, Disclosure Research: Feview And Synthesis. Journal of Accounting Literature, v. 22, p. 1-44, 2003.

BIZELLI, J. S.; ALBUQUERQUE, A. A.; SOUZA, K. G. Impacto do Nível de disclosure no custo de capital das empresas brasileiras de capital aberto do setor de construção civil. Revista de Administração da Universidade Federal de Santa Maria, v. 10, n. 4, p. 592-613, 2017.

BLISS, M. A.; GUL, F. A. Political connection and cost of debt: Some Malaysian evidence. Journal of Banking \& Finance, v. 36, n. 5, p. 1520-1527, 2012.

BORISOVA, G.; FOTAK. V.; HOLLAND, K.; MEGGINSON, W. L. Government ownership and the cost of debt: Evidence from government investments in publicly traded firms. Journal of Financial Economics, v. 118, n. 1, p. 168-191, 2015.

BOUBAKRI, N.; GUEDHAMI, O.; MISHRA, D.; SAFFAR, W. Political connections and the cost of equity capital. Journal of Corporate Finance, v. 18, n. 3, p. 541-559, 2012.

BREY, N. K.; CAMILO, S. P. O.; MARCON, R.; BANDEIRA DE MELLO, R. Conexões políticas das empresas por estruturas de propriedade: uma abordagem do governo como acionista. RACE-Revista de Administração, Contabilidade e Economia, v. 11, n. 2, p. 319$350,2011$.

BRINKERHOFF, D. W. Assessing political will for anti-corruption efforts: an analytic framework. Public Administration and Development: The International Journal of Management Research and Practice, v. 20, n. 3, p. 239-252, 2000.

CAMILO, S. P. O.; MARCON, R.; BANDEIRA DE MELLO, R. Conexões políticas das firmas e seus efeitos na performance: uma convergência entre as perspectivas da governança e da dependência de recursos-um ensaio teórico. Revista Alcance, v. 19, n. 2, p. 241-258, 2012.

CANELA, R.; MARIETTO, M. L. Impacto das Estratégias de Sustentabilidade Empresarial no Custo de Capital Próprio das Empresas Brasileiras. Revista Administração em Diálogo, v. 20, n. 1, p. 82-102, 2017. 
CORRAR, L. J.; PAULO, E.; DIAS FILHO, J. M. Análise multivariada: para os cursos de Administração, Ciências Contábeis e Economia. 01. Ed. São Paulo: Atlas, 2014.

COSTI, R. M.; SOARES, R. O. Determinantes do custo de capital implícito das empresas negociadas na BM\&FBovespa. Contabilidade, Gestão e Governança, v. 17, n. 1, p. 56-74, 2014.

DEEGAN, C.; RANKIN, M. Do Australian companies report environmental news objectively? An analysis of environmental disclosures by firms prosecuted successfully by the Environmental Protection Authority. Accounting, auditing \& accountability journal, v. 9, n. 2, p. 50-67, 1996.

EPSTEIN, M. J.; FREEDMAN, M. Social disclosure and the individual investor. Accounting, Auditing \& Accountability Journal, v. 7, n. 4, p. 94-109, 1994.

FELDMAN, S.J.; SOYKA, P.A.; AMEER, P.G. Does improving a firm's environmental management system and environmental performance result in a higher stock price? Journal of Investing, v. 6, n. 4, p. 87-97, 1997.

FENG, Y. Relation research between information disclosure and capital cost of Chinese listed company. In: Advanced Computational Intelligence (ICACI) 5., 2012 Nanjing, Jiangsu. p. 927-931, 2012

FERNANDES, S. M. A influência do disclosure ambiental na estrutura de capital das empresas brasileiras listadas na BM\&FBovespa . Sociedade, Contabilidade e Gestão, v. 7, n. 2, p. 4154, 2012.

FONSEKA, M.; RAJAPAKSE, T.; RICHARDSON, G. The effect of environmental information disclosure and energy product type on the cost of debt: Evidence from energy firms in China. Pacific-Basin Finance Journal, v. 49, n. 1, p. 1-24, 2018.

FORTI, C. A. B.; PEIXOTO, F. M.; ALVES, D. L. Fatores determinantes do pagamento de dividendos no Brasil. Revista Contabilidade \& Finanças, v. 26, n. 68, p. 167-180, 2015.

FREEMAN, R. E.; EVAN, W. M. Corporate governance: A stakeholder interpretation. Journal of behavioral economics, v. 19, n. 4, p. 337-359, 1990.

FRÍAS-ACEITUNO, J. V.; RODRÍGUEZ-ARIZA, L.; GARCÍA-SÁNCHEZ, I. M. Is integrated reporting determined by a country's legal system? An exploratory study. Journal of cleaner production, v. 44, n. 1, p. 45-55, 2013. 
GE, W.; LIU, M. Corporate social responsibility and the cost of corporate bonds. Journal of Accounting and Public Policy, v. 34, n. 6, p. 597-624, 2015.

GHOUL, S. E.; GUEDHAMI, O.; KWOK, C. C. Y.; MISHRA, D. R. Does corporate social responsibility affect the cost of capital?. Journal of Banking \& Finance, v. 35, n. 9, p. 23882406, 2011.

GONÇALVES, R. S.; MEDEIROS, O. R.; NIYAMA, J. K.; WEFFORT, E. F. J. Social disclosure e custo de capital próprio em companhias abertas no Brasil. Revista Contabilidade \& Finanças - USP, v. 24, n. 62, p. 113-124, 2013.

GOSS, A.; ROBERTS, G. The impact of corporate social responsibility on the cost of bank loans. Journal of Banking \& Finance, v. 35, n. 7, p. 1794-1810, 2011.

GRAY, R.; BEBBINGTON, J. An account of sustainability: failure, success and a reconceptualization. Critical perspectives on accounting, v. 12, n. 5, p. 557-587, 2001.

GUENSTER, N.; BAUER, R.; DERWALL, J.; KOEDIJK, K. The economic value of corporate eco-efficiency. European Financial Management, v. 17, n. 4, p. 679-704, 2011.

GUJARATI, D. N. Econometria básica. 04. Ed. Rio de Janeiro: Elsevier, 2006.

HOEPNER, A.; OIKONOMOU, I.; SCHOLTENS, B.; SCHRODER, M. The effects of corporate and country sustainability characteristics on the cost of debt: An international investigation. Journal of Business Finance \& Accounting, v. 43, n. 1-2, p. 158-190, 2016.

IUDÍCIBUS, S.; LOPES, A. B. Teoria Avançada da Contabilidade. Atlas, São Paulo: 2004.

JACKOWICZ, K.; KOZLOWSKI, L.; MIELCARZ, P. Political connections and operational performance of non-financial firms: New evidence from Poland. Emerging Markets Review, v. 20, p. 109-135, 2014.

JAMALI, D.; SAFIEDDINE, A. M.; RABBATH, M. Corporate governance and corporate social responsibility synergies and interrelationships. Corporate Governance: An International Review, v. 16, n. 5, p. 443-459, 2008.

JENSEN, M. C.; MECKLING, W. H. Theory of the firm: Managerial behavior, agency costs and ownership structure. Journal of financial economics, v. 3, n. 4, p. 305-360, 1976. 
JO, H.; HARJOTO, M. A. The causal effect of corporate governance on corporate social responsibility. Journal of business ethics, v. 106, n. 1, p. 53-72, 2012.

KAYMAK, T.; BEKTAS, E. Corporate social responsibility and governance: information disclosure in multinational corporations. Corporate Social Responsibility and Environmental Management, v. 24, n. 6, p. 555-569, 2017.

LI, S.; LIU, C. Quality of Corporate Social Responsibility Disclosure and Cost of Equity Capital: Lessons from China. Journal Emerging Markets Finance and Trade, v. 54, n. 11, p. 2472-2494, 2018.

LIEDONG, T. A.; RAJWANI, T. Mediation in the Link Between Political Ties and Cost of Debt in Ghana: An Agency Perspective. Academy of Management Proceedings, v. 1, p. 15447, 2017.

LIU, Q.; VILLIERS, C. Does the Provision of Voluntary Corporate Social Responsibility Disclosure Influence the Cost of Equity Capital? Evidence from Australia and the United Kingdom. Corporate Ownership and Control, v. 8, n. 4, p. 201-213, 2011.

LOPES, A. B.; MARTINS, E. Teoria da Contabilidade: uma nova abordagem. Atlas, São Paulo: 2005.

LORRAINE, N.H.J.; COLLISON, D.J.; POWER, D.M. An Analysis of the Stock Market Impact of Environmental Performance Information. Accounting Forum. v. 28, n. 1, p. 7-26, 2004.

MACEDO, J. M. A.; SILVA, C. A. T.; MACHADO, M. A. V. Conexões políticas e as empresas brasileiras: um estudo experimental sobre as decisões de investimento no mercado de capitais. Advances in Scientific and Applied Accounting, v. 8, n. 2, p. 157-178, 2015.

MANSI, S. A.; MAXWELL, W. F.; MILLER, D. P. Analyst forecast characteristics and the cost of debt. Review of Accounting Studies, v. 16, n. 1, p. 116-142, 2011.

MARTÍNEZ-FERRERO, J.; GARCÍA-SÁNCHEZ, I. M. Sustainability assurance and cost of capital: Does assurance impact on credibility of corporate social responsibility information? Business Ethics: A European Review, v. 26, n. 3, p. 223-239, 2017.

MATOS, B.; REINA, D.; ENSSLIN, S. R.; REINA, D. R. M. Evidenciação voluntária do capital intelectual de natureza social e ambiental da empresa natura cosméticos S.A. no período 
entre 2003 e 2008. Contextus - Revista Contemporânea de Economia e Gestão, v. 9, n. 1, p. 67-77, 2011.

MICHAELS, A.; GRUNING, M. Relationship of corporate social responsibility disclosure on information asymmetry and the cost of capital. Journal of Management Control, v. 28, n. 3, p. 251-274, 2017.

NARDI, P. C. C.; SILVA, R. L. M.; NAKAO, S. H.; VALlE, M. R. A relação entre gerenciamento de resultados contábeis e o custo de capital das companhias abertas brasileiras. Revista Universo Contábil, v. 5, n. 4, p. 06-26, 2009.

PEIXOTO, F. M.; PAINS, M. B.; ARAÚJO, A. A.; GUIMARÃES, T. M. Custo de capital, endividamento e sustentabilidade empresarial: um estudo no mercado de capitais brasileiro no período de 2009 a 2013. RACE: Revista de Administração, Contabilidade e Economia, v. 15, n. 1, p. 39-66, 2016.

PINHEIRO, B. G.; LUCA, M. M. M.; VASCONCELOS, A. C. Conexões políticas nas maiores companhias listadas na BM\&FBovespa. READ-Revista Eletrônica de Administração, v. 22, n. 2, p. 394-418 2016.

REVERTE, C. The impact of better corporate social responsibility disclosure on the cost of equity capital. Corporate Social Responsibility and Environmental Management, v. 19, n. 5, p. 253-272, 2012.

RIBEIRO, A. M.; NASCIMENTO, L. F.; VAN BELLEN, H. M. Evidenciação ambiental: análise comparativa multissetorial entre Brasil, Estados Unidos e Inglaterra. Contextus Revista Contemporânea de Economia e Gestão, v. 7, n. 1, 2009.

RICHARDSON, A. J.; WELKER, M. Social disclosure, financial disclosure and the cost of equity capital. Accounting, organizations and society, v. 26, n. 7-8, p. 597-616, 2001.

ROVER, S. Disclosure socioambiental e custo de capital próprio de companhias abertas no Brasil. 2013. 197 f. Tese (Doutorado em Controladoria e Contabilidade) - Faculdade de Economia, Administração e Contabilidade da Universidade de São Paulo. São Paulo, Brasil, 2013.

ROVER, S.; BORBA, J. A.; MURCIA, F. D. Características do disclosure ambiental de empresas brasileiras potencialmente poluidoras: Análise das demonstrações financeiras e dos relatórios de sustentabilidade do período de 2005 a 2007. Contextus - Revista Contemporânea de Economia e Gestão, v. 7, n. 1, art. 202, p. 23-36, 2009. 
INFLUÊNCIA DAS CONEXÕES POLÍTICAS E DA EVIDENCIAÇÃO SOCIOAMBIENTAL NO CUSTO DE CAPITAL

SANTOS, A. K. A. Custo e ganho da dívida e as conexões políticas: um estudo em empresas listadas na BM\&FBOVESPA. 2017. 74 f. Dissertação (Mestrado em Administração) - Centro de Ciências Sociais Aplicadas, Universidade Federal da Paraíba, João Pessoa, Brasil, 2017.

SHARFMAN, M. P.; FERNANDO, C. S. Environmental risk management and the cost of capital. Strategic management journal, v. 29, n. 6, p. 569-592, 2008.

SPITZECK, H.; HANSEN, E. G. Stakeholder governance: how stakeholders influence corporate decision making. Corporate Governance: The international journal of business in society, v. 10, n. 4, p. 378-391, 2009.

TEE, C. M. Political connections, institutional monitoring and the cost of debt: evidence from Malaysian firms. International Journal of Managerial Finance, v. 14, n. 2, p. 210-229, 2018.

WU, W.; WU, C.; ZHOU, C.; WU, J. Political connections, tax benefits and firm performance: Evidence from China. Journal of Accounting and Public policy, v. 31, n. 3, p. 277-300, 2012. 